\title{
UM PASSEIO PELA ÁFRICA: PRÁTICAS PEDAGÓGICAS SIGNIFICATIVAS NO CONTEXTO DA LEI No ${ }^{\circ} \mathbf{1 0 . 6 3 9 / 2 0 0 3}$
}

\author{
João Paulo Roberti Junior \\ Universidade Federal de Santa Catarina - UFSC. Florianópolis, Brasil \\ Fernanda Ax Wilhelm \\ Universidade Federal de Roraima - UFRR. Boa Vista, Brasil \\ Ana Paula da Rosa Deon \\ Universidade Federal de Roraima - UFRR. Boa Vista, Brasil \\ Idonézia Collodel Benetti \\ Universidade Federal de Santa Catarina - UFSC. Florianópolis, Brasil
}

\begin{abstract}
Resumo. Este artigo é resultado de uma experiência pedagógica, realizada em uma escola pública estadual de Santa Catarina, que buscou aliar um projeto interdisciplinar sobre a Consciência Negra ao contexto da Lei $\mathrm{N}^{\circ}$ 10.639/2003. As disciplinas envolvidas foram Matemática, Geografia e Língua Inglesa, que investiram na possibilidade de atrelar seus respectivos conteúdos, com assuntos relativos às africanidades. Os trabalhos gravitaram em torno de pesquisas sobre os países do continente africano, na sala de informática da escola, lócus principal para a elaboração das buscas. A experiência possibilitou o desenvolvimento de um trabalho cooperativo e colaborativo, que proporcionou a formação de alianças, alavancando os pontos fortes de cada um, com a ajuda dos parceiros e incentivou a construção do conhecimento, vinculado a um contexto social crítico, em uma comunidade de aprendizagem.
\end{abstract}

Palavras-chave: Interdisciplinaridade, Aprendizagem significativa, Cooperação, Colaboração.

\section{UN TOUR DE ÁFRICA: PRÁCTICAS EDUCATIVAS RELEVANTES EN EL CONTEXTO DE LA LEY N ${ }^{\circ} 10.639 / 2003$}

\begin{abstract}
Resumen. Este artículo es el resultado de una experiencia de aprendizaje, que tuvo lugar en una escuela estatal en Santa Catarina, que trató de combinar un proyecto interdisciplinario sobre la Conciencia Negra según lo previsto por la Ley $\mathrm{N}^{\circ}$ 10.639/2003. Las asignaturas involucradas han sido Matemáticas, Geografía e Idioma Inglés, cuyo contenido se combinó con temáticas relacionadas con cuestiones africanas. En los trabajos se han desarrollado investigaciones sobre los países africanos en la sala de informática de la escuela, la localización principal para la elaboración de las búsquedas. La experiencia permitió el desarrollo de un trabajo cooperativo y colaborativo, que preveía la formación de alianzas que aprovechan las fortalezas de cada uno, con la ayuda de compañero y alentó a la construcción del conocimiento de forma crítica en una comunidad de aprendizaje.
\end{abstract}

Palabras clave: Interdisciplinariedad, Aprendizaje significativa, Cooperación, Colaboración. 


\title{
A JOURNEY AROUND AFRICA: MEANINFUL EDUCATIONAL PRACTICES IN THE CONTEXT OF LAW $\mathrm{N}^{\circ} \mathbf{1 0 . 6 3 9 / 2 0 0 3}$
}

\begin{abstract}
This article is the result of a learning experience, taking place in a state school in Santa Catarina, which sought to combine an interdisciplinary project related to the Black Consciousness within the context of the Law $N^{\circ} 10.639 / 2003$. The subjects involved were Mathematics, Geography and English Language, which content was combined with African matters. The works gravitated around African countries, in the computer room of the school, the main place for the researches. The experience enabled the development of a cooperative and collaborative work, which provided the construction of alliances that empower the strengths of each student, with the help of peers, at the same time it encouraged the construction of knowledge, linked to a critical social context in a learning community.
\end{abstract}

Keywords: Interdisciplinarity, Meaningful learning, Cooperation, Collaboration.

\section{Considerações iniciais}

A Lei n¹0.639, de 2003, ampara a inclusão da temática história da África e dos africanos, para ser debatida no espaço escolar brasileiro, além de possibilitar a discussão sobre a luta dos negros no Brasil, a cultura negra brasileira e o negro na formação da sociedade nacional. Esse é um avanço que inclui, na Lei de Diretrizes e Bases da Educação (LDB), a obrigatoriedade da temática 'História e Cultura Afro-Brasileira'.

Nessa seara, foram aprovadas as Diretrizes Curriculares Nacionais (PCNs) para a Educação das Relações Étnico-Raciais pelo Parecer $n^{\circ} \mathrm{CNE} / \mathrm{CP}$, de 10 de março de 2004. As diretrizes buscam assegurar "O direito à igualdade de condições de vida e de cidadania, assim como garantem igual direito às histórias e culturas que compõem a nação brasileira, além do direito de acesso às diferentes fontes da cultura nacional a todos brasileiros" (Brasil, 2006, p. 229).

Nesse cenário, este trabalho tem por objetivo relatar a experiência realizada em uma escola pública estadual de Santa Catarina, no mês que abriga o dia da Consciência Negra. A escola, situada em um bairro de periferia de Florianópolis, investiu, com base na Lei ${ }^{\circ} 10.639$, em conteúdos relativos às africanidades, agregando-os ao seu Projeto Político Pedagógico (PPP).

Uma dessas disciplinas foi a Língua Inglesa que, de acordo com os PCNs, possibilita a expansão das habilidades comunicativas e ampliação cultural por meio da compreensão das diferentes formas de comunicação, com a possibilidade de abertura para que o estudante possa (re)constituir sua carga cultural e linguística. Dessa forma, as aulas de língua estrangeira vão muito além do que ensinar regras gramaticais, abrindo espaço para o desenvolvimento de estratégias e habilidades para lidar com outro idioma, além de estimular o pensamento crítico do aluno. Para isso, é necessário que os aspectos históricos, ideológicos, culturais e políticos, às vezes esquecidos e neutralizados nos 
discursos dos professores, sejam debatidos com os alunos, fazendo deles sujeitos ativos da ação, em um espaço onde eles tenham vez e voz (Santos, 2011, Freire, 2006).

Para isso, o projeto ‘África em nós' tem sido trabalhado em várias disciplinas ao longo de cada ano letivo e, neste estudo, são apresentadas atividades realizadas nas disciplinas de Língua Inglesa, Geografia e Matemática, ao longo do mês de outubro de 2014, em preparação para a exposição em conjunto com as festividades realizadas na escola no mês de novembro do referido ano, ocasião em que toda a comunidade escolar é convidada e se faz presente.

Pedagogicamente, além da leitura e compreensão de textos em língua inglesa, o projeto desenvolvido nas aulas teve os seguintes objetivos: a) trabalhar a localização geográfica dos países africanos; b) apontar diferenças culturais, geográficas e políticas entre os países africanos em si; c) averiguar em quais países africanos se fala português e em quais se fala inglês; d) investigar o sistema de ensino em alguns países africanos; d) comparar o sistema de ensino dos países africanos com o sistema de ensino brasileiro; e) mostrar algumas diferenças culturais, geográficas e políticas entre os países do continente africano e o Brasil; apontar diferenças culturais, geográficas e políticas entre os países africanos em si; f) calcular taxas e percentuais, com base nos dados estatísticos encontrados; g) apresentar oralmente os trabalhos pesquisados; e h) expor o resultado dos trabalhos nas dependências da escola.

Partiu-se do entendimento de que a aprendizagem é significativa quando, em vez de memorizar, o aluno relaciona a nova informação ao seu repertório cognitivo já existente, incorporando-a a conteúdos que foram aprendidos anteriormente (Ausubel, 1962). Assim, a aprendizagem de novos conhecimentos se baseia no que já é conhecido, ou seja, a construção do conhecimento começa com a observação e o reconhecimento de acontecimentos, por meio de conceitos já adquiridos; é a aprendizagem por meio da construção de uma rede de conceitos que vai sendo acrescentada e ampliada.

Nesse processo, há formação de conexões cerebrais entre as novas e as informações prévias do aprendiz (Valadares e Moreira, 2009); em que o primeiro é comparado e contrastado com o segundo, que existe na estrutura cognitiva, interagindo com a estrutura de conhecimento já formada. Se uma pessoa tem conteúdo relevante em sua estrutura cognitiva existente, que possibilite o relacionamento da nova informação com o conhecimento adquirido, então há estofo para que aprendizagem seja significativa, já que não se pode identificar e reconhecer aquilo que não se sabe.

A aquisição de conhecimento, portanto, obriga o indivíduo a considerar a informação nova e, com base em suas experiências prévias, pontos de vista pessoais e background cultural, construa uma interpretação da informação que está sendo apresentada a ele, assim o aluno elabora regras novas ou adaptadas para dar sentido ao mundo. Nesse caso, se não há conhecimento prévio relevante na estrutura cognitiva, para o qual a nova informação possa relacionar-se, só pode ser aprendida de forma mecânica e essa aprendizagem está mais propensa a ser esquecida. 
A noção de que as escolas devem rejeitar os modelos de ensino mecânicos e repetitivos foi enfatizada por vários estudiosos:

- John Dewey: propôs que alunos deveriam estar envolvidos e engajados no mundo real, em oficinas práticas, em que eles poderiam demonstrar o seu conhecimento, exercendo criatividade e colaboração. Ele advogou em favor de uma educação ancorada na experiência real, em que devem ser oferecidas oportunidades para pensar e articular pensamentos (Campbell, 1995).

- Jean Piaget: rejeitou a ideia de que a aprendizagem era a assimilação passiva de determinado conhecimento. Ele propôs que o ato de aprender deve ser um processo dinâmico, que compreende as fases sucessivas de adaptação à realidade, durante o qual os alunos constroem o conhecimento ativamente, criando e testando suas próprias teorias do mundo (Atherton, 2013).

- Jerome Bruner: baseou-se na noção de que a aprendizagem é um processo ativo e social no qual os alunos constroem novas ideias ou conceitos, com base em seu conhecimento atual. Para ele, a aprendizagem deve ser um processo de descoberta, onde os alunos constroem o seu próprio conhecimento, com o diálogo ativo, e devem ser incentivados a esclarecer a si mesmo através da reflexão, sempre com base no seu conhecimento existente (Bruner e Haste, 1987).

- Lev Vygotsky: introduziu a ideia de que as crianças podem realizar tarefas mais desafiadoras, quando assistidas por indivíduos mais avançados e competentes. Com isso, afirma que a interação social tem um papel vital no processo de desenvolvimento cognitivo. Ele descreveu isso como a zona de desenvolvimento proximal - tarefas que uma criança pode realizar com a ajuda e orientação de outras pessoas (Vygotsky, 1978).

Assim, criatividade, colaboração, construção de conhecimentos, diálogo ativo, entre outros atributos, indicam que, nas salas de aula atuais, já não há mais espaço para os modelos tradicionais, onde o professor apenas transfere conhecimentos para seus alunos. Esse deve, prioritariamente, ter um papel ativo na aprendizagem para que todo o processo ocorra com mais fluidez e eficiência.

Estilos de ensinar, com base em abordagens que têm o aluno no centro do processo de ensino/aprendizagem, marcam um esforço consciente no sentido de se deslocar dos modelos tradicionais, orientados para a memorização, abordagem mais centrada no aluno. Em tal ambiente, o professor não pode estar no comando do processo ensino/aprendizagem, uma vez que a opinião de todos, levando em consideração a realidade de cada um, vai ser diferente e os alunos entrarão no processo de aprendizagem já possuindo suas próprias construções de mundo, que devem ser valorizadas e aproveitadas. 
Nessa perspectiva, quando o professor menciona a palavra 'África', cada aluno, a partir do seu conhecimento prévio, tem uma ideia do que o continente é. Nessa ação, há trabalho mental, crucial para a construção de significados, que acontece na mente. Ações físicas como 'colocar a mão na massa' podem ser necessárias para o aprendizado, especialmente para as crianças, mas não são suficientes; é fundamental oferecer atividades que desenvolvam tanto a mente como as mãos - atividades reflexivas (Dewey, 2011). Nesse sentido, o aluno tem papel ativo e precisa fazer algo, já que a aprendizagem não é a aceitação passiva do conhecimento que existe além do contexto escolar; antes disso, é um fenômeno que preconiza a necessidade deve se envolver com o mundo.

Nessa abordagem, ao preparar as aulas, o professor tem que delinear seus trabalhos, priorizando procedimentos que levem o aluno a pensar sobre a própria aprendizagem - não sobre o assunto/lição a ser ensinado. Não há conhecimento independente do significado atribuído à experiência construída pelo aluno, ou pela comunidade de aprendizes (Feldman, 2010). Assim, no fazer pedagógico, que leva em consideração a construção de conhecimentos, o professor deve ter a intenção permanente de deixar claro para que a estrutura do mundo independente do aprendiz; o professor é o agente facilitador que vai ajudá-lo a compreender o mundo.

Ambientes de aprendizagem, preocupados em construir conhecimento e potencializar o aluno para buscar, filtrar, analisar e refletir sobre as informações fornecidas e, posteriormente, comentar sobre o que aprendeu, possibilitarão, como resultado, compreensão e aprendizagem. Ainda, a aprendizagem em grupo reduz a disseminação de preconceitos e atrocidades entre os diversos grupos e ajuda a construir uma sociedade de informação moral e científica, mais adequada ao cenário da contemporaneidade. Aprender é um ato contextual: não se aprende fatos isolados e separados do resto dos acontecimentos da vida. Os alunos aprendem em relação com o que mais sabem e com o que acreditam, incluindo seus preconceitos e medos (Egan e Judson, 2008). Nesse sentido, a aprendizagem é ativa e social e não admite que possa haver separação de todo o aprendizado feito durante a vida.

Também, o aprendizado está intimamente associado à conexão com outras dinâmicas - professores, colegas, família, bem como conhecidos casuais, incluindo as pessoas que circulam e interagem no mesmo espaço social. Pois, grande parte da educação tradicional é dirigida para isolar o aluno de toda interação social, no sentido de ver o processo educativo como um relacionamento um para um - entre o aluno e o objeto a ser aprendido (Bohonos, 2013). Em contraste, a educação que tem o aluno no centro do processo reconhece o aspecto social da aprendizagem e usa a conversa e interação com outros, bem como a aplicação do conhecimento enquanto aspecto integral da aprendizagem. Dessa forma, os professores serão mais propensos a ser bemsucedidos em seus esforços para educar se reconhecerem esse princípio, em vez de tentar evitá-lo. 
A interação usada em benefício do processo ensino/aprendizagem tem apresentado efeitos positivos sobre o desempenho escolar, pois tem focado nas relações interétnicas, construindo a aceitação de alunos com mais dificuldades acadêmicas. Além disso, possibilita a melhoria da autoestima e das atitudes e comportamentos em relação à escola e professores (Slavin, 2010). Tantos acréscimos são justificados, porque o fazer em sala de aula possibilita que os alunos: a) valorizem seus pares e sejam valorizados por eles; b) sintam-se motivados a ajudar uns aos outros a aprender; c) assumam a responsabilidade por sua própria aprendizagem; d) traduzam a linguagem do professor, quando estão explicando o assunto para outro; e) respeitem as diferenças entre seus pares; f) tenham um ambiente de aprendizagem mais leve e divertido; g) aprendam a ver as situações do ponto de vista do outro, justificando os seus para, então, analisar ideias.

Neste trabalho, os conteúdos estiveram em consonância com a noção de que a ação de uma política educacional, voltada para um campo cultural, é ativa e relacional. Isso implica entender que o processo cultural é um processo posto em ação, quando um conjunto de atores sociais, moldados com diferentes significados e práticas culturais se mobilizam (Alvaréz, Dagnino e Escobar, 2000).

\section{Procedimentos metodológicos}

Esta sistematização consiste em um relato de experiência que descreve alguns procedimentos pedagógicos realizados no ano de 2014, em uma escola pública estadual de um bairro da periferia de Florianópolis. Aproximadamente 120 alunos participaram das aulas interdisciplinares, que fizeram parte do projeto 'África em nós'. As atividades foram aplicadas junto aos alunos do Ensino Fundamental ( $7^{\circ}$. e $8^{\circ}$. ano), ao longo de 20 aulas -8 de Matemática e 12 de Inglês.

Os trabalhos se desenvolveram em torno de pesquisas que informaram os participantes sobre o continente africano. As buscas foram realizadas na língua-alvo (língua inglesa), em sites da Internet. Apesar de ter sido delimitado um tema, as buscas situaram outros assuntos relacionados à África, uma vez que a pesquisa possibilitou o encontro com outros conteúdos, que permitiram conexão com o tema estipulado.

A sala de informática foi o lócus principal para a elaboração da pesquisa. Nesse espaço, os estudantes foram auxiliados pelo professor de informática, além da professora de Inglês. As turmas foram divididas em grupos e os alunos foram convidados para 'passear' pelo continente africano e escolher o país que eles entendessem ser mais interessante, sobre o qual deveriam pesquisar e, posteriormente, socializar o resultado das pesquisas com a turma. Também foi solicitado que os achados africanos fossem comparados com a realidade brasileira. Terminada a pesquisa e a elaboração das apresentações, cada grupo foi responsável por compartilhar as novidades com o grande grupo. 
Figuras 1 e 2: Alunos pesquisando na sala de informática
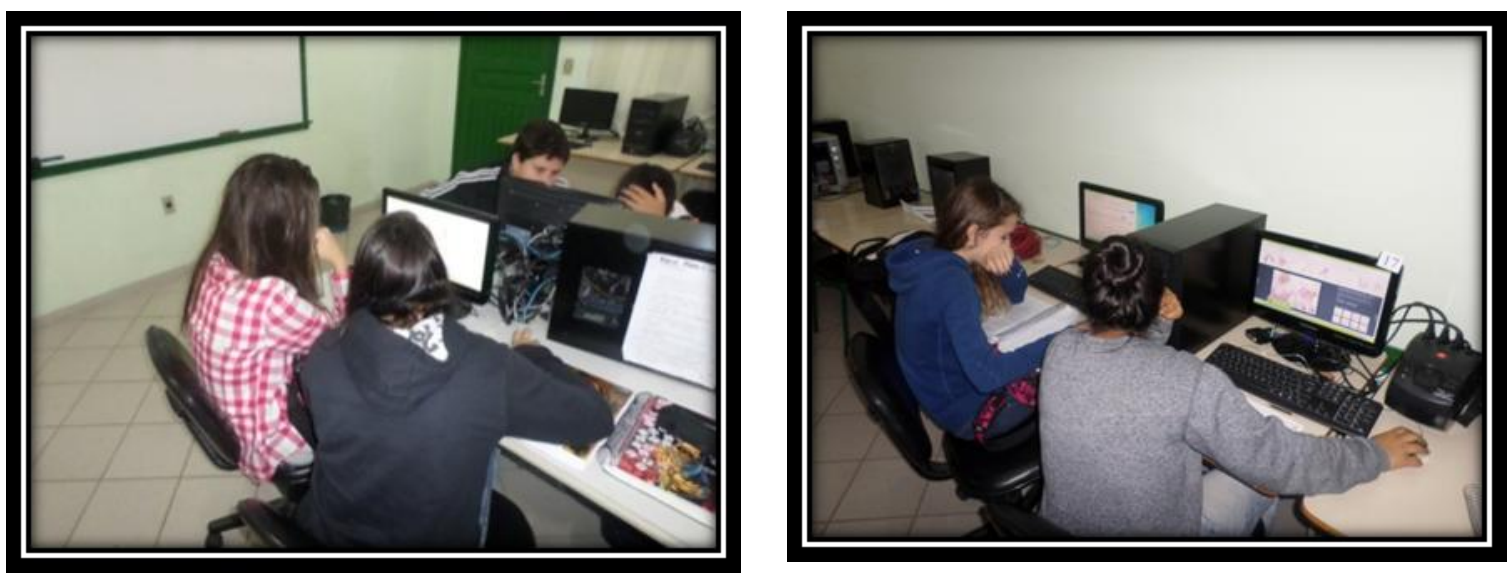

Fonte: Acervo da escola

Figuras 3 e 4: Alunos socializando suas pesquisas
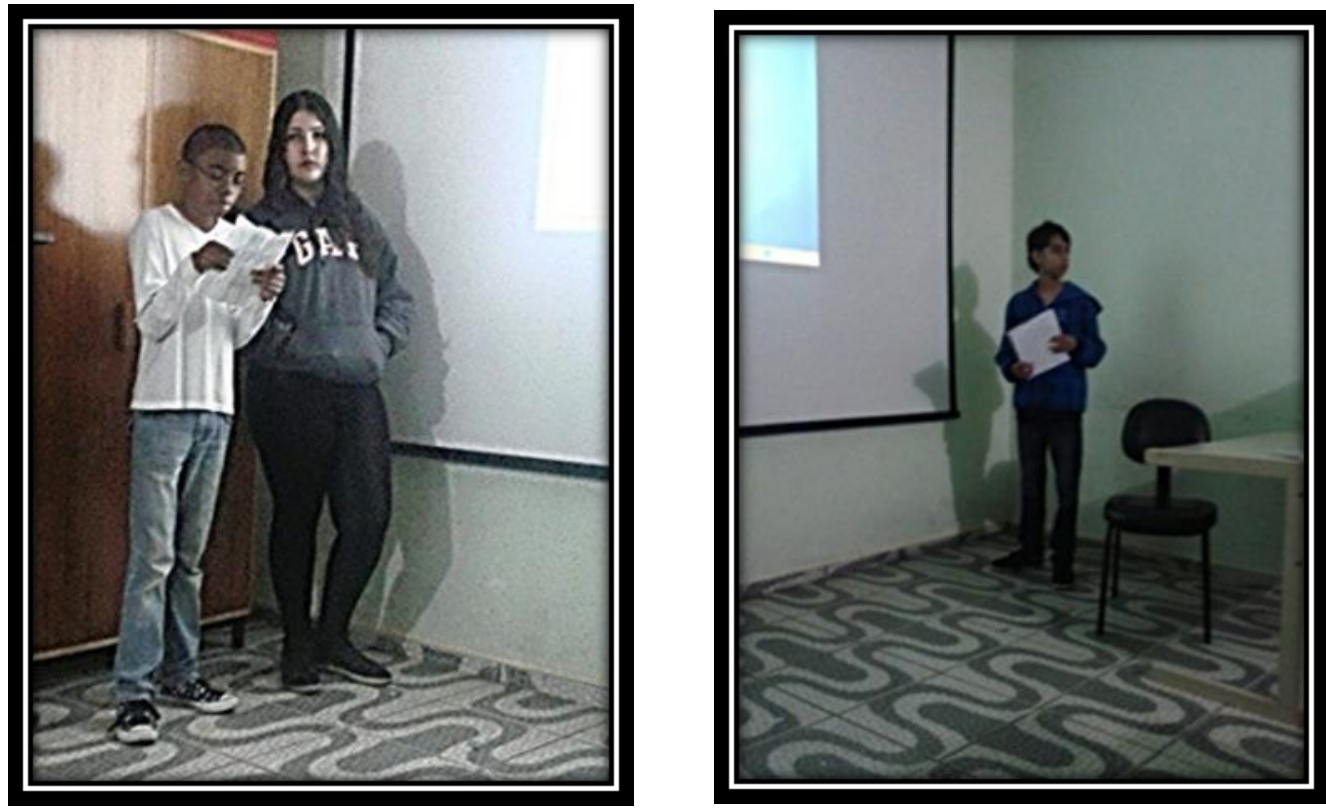

Fonte: Acervo da escola

No momento das explanações, houve um aquecimento do assunto e preparação dos alunos para os trabalhos, por meio da utilização dos seguintes vídeos: 1) África na Escola - Lei $N^{\circ} 10.639$ (https://www.youtube. com/watch?v=9EXH-GPgFE), 2) Educação na África - A mensalidade (https://www. youtube.com/watch?v=h2YU0q7rnM), 3) Uma escola em África - pode nos ajudar a construir uma melhor? (https://www.youtube. com/watch?v=cijkdO7 jYIo). Eram vídeos de curta duração, com documentários de interesse dos estudantes.

Os vídeos foram discutidos e houve comparações entre as realidades brasileira e africana. Também, aproveitando o conteúdo dos vídeos, foi comentado sobre como é a 
estrutura geral do sistema educacional brasileiro. Então, a partir de conhecimentos prétrabalhados, os conteúdos de Inglês, Geografia e Matemática foram abordados, concomitantemente, conforme apresentado na Tabela 1. A contextualização geográfica foi trabalhada pela professora de Língua Inglesa, já os conteúdos relativos às informações sobre cálculos, foram desenvolvidos nas aulas de Matemática, sobre dados estatísticos da África na resolução de exercícios baseados em texto previamente selecionado.

Tabela 1: Disciplina, conteúdo trabalhado e modalidade (individual ou parceria)

\begin{tabular}{|c|c|c|}
\hline Disciplina & Conteúdo & Modalidade \\
\hline $\begin{array}{c}\text { Inglês } \\
\text { Geografia }\end{array}$ & $\begin{array}{l}\text { Passeio virtual pelo continente africano para reconhecimento da } \\
\text { localização dos seus países (sites em inglês). }\end{array}$ & $\begin{array}{l}\text { Pares de } \\
\text { trabalho }\end{array}$ \\
\hline $\begin{array}{c}\text { Inglês } \\
\text { Geografia }\end{array}$ & $\begin{array}{l}\text { Aula expositiva, na sala de informática, para o reconhecimento } \\
\text { dos países do continente africano que falam inglês e português. }\end{array}$ & $\begin{array}{c}\text { Aula } \\
\text { Expositiva }\end{array}$ \\
\hline $\begin{array}{l}\text { Inglês } \\
\text { Geografia }\end{array}$ & $\begin{array}{l}\text { Distribuição de mapas - duas cores diferentes foram escolhidas } \\
\text { para identificar os países que falam cada uma das línguas } \\
\text { mencionadas } \\
\text { coloring.jpg) }\end{array}$ & $\begin{array}{l}\text { Trabalho } \\
\text { individual }\end{array}$ \\
\hline Inglês & $\begin{array}{l}\text { Música: "Ebony and Ivory" - distribuição da letra com lacunas, } \\
\text { para ser preenchida, à medida que a música era ouvida } \\
\text { https://www.youtube.com/ watch?v=TztiJN6yiik }\end{array}$ & Individual \\
\hline Inglês & Interpretação da letra da música & Pares \\
\hline Inglês & $\begin{array}{l}\text { Escolha de um país africano para pesquisar sobre seu sistema } \\
\text { educacional - cada equipe de trabalho era livre para escolher um } \\
\text { país. }\end{array}$ & $\begin{array}{l}\text { Grupos de } \\
\text { trabalho }\end{array}$ \\
\hline Inglês & $\begin{array}{l}\text { Leitura e interpretação de texto (em inglês) sobre dados } \\
\text { estatísticos gerais da Âfrica. }\end{array}$ & $\begin{array}{l}\text { Pares de } \\
\text { trabalho }\end{array}$ \\
\hline Matemática & $\begin{array}{l}\text { Leitura de texto (em português) sobre dados estatísticos da África } \\
\text { e resolução de exercícios de matemática com base no texto. }\end{array}$ & Individual \\
\hline Matemática & $\begin{array}{l}\text { Leitura e interpretação de gráficos com dados estatísticos sobre: } \\
\text { distribuição de alunos em escola pública em 2014; percentuais de } \\
\text { alunos, professores e escolas; distribuição de alunos por sexo e } \\
\text { série. }\end{array}$ & $\begin{array}{l}\text { Grupos de } \\
\text { trabalho }\end{array}$ \\
\hline Matemática & $\begin{array}{l}\text { Construção de gráficos com os dados sobre evasão escolar nos } \\
\text { países pesquisados. }\end{array}$ & $\begin{array}{l}\text { Grupos de } \\
\text { trabalho }\end{array}$ \\
\hline $\begin{array}{l}\text { Geografia } \\
\text { Inglês }\end{array}$ & Preparação de pôsteres com o conteúdo da pesquisa. & $\begin{array}{l}\text { Grupos de } \\
\text { trabalho }\end{array}$ \\
\hline $\begin{array}{l}\text { Geografia } \\
\text { Inglês }\end{array}$ & Apresentação oral dos trabalhos para toda a turma. & $\begin{array}{l}\text { Grupos de } \\
\text { trabalho }\end{array}$ \\
\hline $\begin{array}{l}\text { Inglês } \\
\text { Geografia }\end{array}$ & $\begin{array}{l}\text { Discussão sobre os trabalhos apresentados e comparação entre os } \\
\text { países africanos (semelhanças e diferenças); comparação entre a } \\
\text { cultura do Brasil e dos países pesquisados e entre a realidade } \\
\text { escolar deles e a realidade escolar brasileira; conclusões e razões } \\
\text { que sustentam as conclusões oferecidas. }\end{array}$ & $\begin{array}{l}\text { Toda a } \\
\text { turma }\end{array}$ \\
\hline $\begin{array}{l}\text { Inglês } \\
\text { Geografia } \\
\text { Matemática }\end{array}$ & $\begin{array}{l}\text { Exposição contendo o conteúdo pesquisado, o mapa da África } \\
\text { com um país trabalhado em destaque e com fotos de escolas } \\
\text { daquele mesmo país. }\end{array}$ & $\begin{array}{c}\text { Grupos de } \\
\text { trabalho }\end{array}$ \\
\hline
\end{tabular}


$\mathrm{Na}$ Matemática, a resolução de problemas esteve baseada em um texto trabalhado pelo docente da disciplina. Foram estimulados desafios que exigiram alguns cálculos e interpretações, como, por exemplo: o que significa dizer que $36 \%$ das crianças de Burundi repetiram algum ano no ensino primário? Qual cálculo matemático é feito para se afirmar que a evasão escolar é de $72 \%$ em Chad? Como interpretar o fato de que na África subsaariana as chances de morrer no parto ou durante a gravidez são 20 vezes maiores do que na América do Norte? Como calcular a razão entre morte e sobrevivência ao parto, quando as estatísticas apontam que uma em cada 16 mulheres que vivem na África subsaariana vai morrer durante o parto ou gravidez e haverá apenas uma morte em cada 4.000 mulheres na América do Norte?

O empenho dos alunos culminou no desejo de realizar uma exposição de fotos que mostrassem a realidade de alguns estabelecimentos de ensino na África, embora esse item não tivesse sido pensado a priori. Essa realização partiu como iniciativa deles, e recebeu o título de 'Schools around Africa' e, a partir dessa ideia, cada grupo recebeu um mapa do continente com sua divisão política, onde deveriam localizar e destacar, na cor desejada, o país trabalhado.

Esse esforço gerou outra ideia: expor, também, resumidamente, os fatos mais interessantes encontrados na pesquisa. Assim, o conteúdo da exposição albergou, além das fotos das escolas, os mapas com cada país trabalhado, cartazes com dados estatísticos e gráficos ilustrativos sobre a evasão escolar naquele continente; além de pôsteres com a concepção dos alunos sobre o que eles acreditassem ser mais interessante ao pesquisar aquelas nações. Todo o material foi exposto no mês de novembro nas dependências da escola por meio de murais, e assim, a comunidade foi informada e convidada para visitar os trabalhos.

\section{Alguns resultados}

Alunos engajados, sala movimentada, perguntas, respostas e discussões: tudo harmonizado com espontaneidade, sentimento e profundas percepções individuais, com a possibilidade do pensamento racional e da reflexão. Um espaço onde se acredita na capacidade de cada indivíduo para crescer e aprender, possibilitando que professores, alunos e conteúdos assumam igual importância na equação de aprendizagem; lugar onde os professores adotam o papel de facilitadores e guias, dando aos alunos a oportunidade de descobrir por si mesmos e de se desenvolver como sujeitos ativos e independentes.

Nesse local, as descobertas realizadas, que foram trazidas para as apresentações em grande grupo, envolveram muitos dados, que despertaram e prenderam a atenção dos alunos durante a investigação sobre o continente africano. Ao pesquisar a estrutura educacional dos países da África, eles foram além do que deveriam ter investigado. Entre tantas descobertas, eles ficaram apreensivos com os muitos fatos e dados estatísticos. Destas descobertas, e após discussões e debates no grande grupo, várias foram as conclusões apontadas. Elas foram listadas por eles, bem como as razões para 
que eles chegassem a tais conclusões, que sustentaram os argumentos da turma. Algumas delas são demonstradas a seguir.

- Conclusão 1: Na África a qualidade de vida é inferior a do Brasil

Razões encontradas: A maioria dos países do continente africano oferece condições de vida inferiores a seus cidadãos, se comparado às condições da população brasileira, porque 32, de 38 países pobres, altamente endividados do mundo, estão na África; metade da população da África vive com menos de US\$ 1 por dia; a África subsaariana é a única região do mundo onde a pobreza aumentou nos últimos 25 anos; as favelas são os lares de $72 \%$ dos cidadãos da África urbana. Embora, no Brasil, também seja possível encontrar situações semelhantes, temos vivido esses problemas em escala bem menor.

- Conclusão 2: Desigualdade entre os sexos é mais acentuada na África

Razões encontradas: Se comparado às condições brasileiras, o sexo feminino tem mais desafios e menos amparo nos países africanos, porque 33 milhões de crianças em idade escolar primária na África subsaariana não vão à escola - 18 milhões dessas crianças são meninas e, embora as taxas de alfabetização tenham melhorado muito nesse País ao longo das últimas décadas, cerca de $40 \%$ dos africanos com mais de 15 anos de idade e $50 \%$ das mulheres acima de 25 anos são analfabetos; o sexo masculino é mais privilegiado com relação ao acesso à educação; quase metade (47\%) das meninas com idade para frequentar o ensino fundamental não vão à escola.

- Conclusão 3: Tanto na África quanto no Brasil, ou em qualquer outro local do planeta, a educação é o meio pelo qual as pessoas podem ter ascensão a melhores empregos e salários, mais esclarecimento e melhor condição de vida

Razões encontradas: a educação é fundamental em qualquer lugar do mundo e na África, porque lá AIDS diminui em aldeias onde existem escolas primárias; na Uganda, é três vezes mais provável que uma criança que deixa de frequentar a escola adquira o vírus HIV positivo, mais tarde na vida, do que uma criança que completa o ensino básico; menos de $20 \%$ das mulheres africanas têm acesso à educação; mulheres africanas iletradas são duas vezes mais propensas a contrair AIDS e têm $50 \%$ menos probabilidade de imunizar (vacinar) seus filhos; os filhos de mulheres africanas, com, pelo menos, cinco anos de escolaridade, têm chance $40 \%$ maior de sobrevivência; para cada ano que uma menina permanece na escola, além de $4^{a}$ série, o seu salário aumenta em 20\%; uma menina que termina o ensino básico tem três vezes menos probabilidade de contrair AIDS; se todas as mulheres na África subsaariana concluíssem o ensino secundário, 1,8 milhões de vidas poderiam ser salvas anualmente. 
- Conclusão 4: As políticas públicas voltadas para a educação têm menos alcance na África

Razões encontradas: há diferenças bem marcantes entre os países da África e Brasil, porque os pais devem pagar taxas para os seus filhos frequentarem a escola, mesmo sendo escolas públicas; menos de três quartos dos adultos da Tanzânia são alfabetizados; os índices de matrículas no ensino primário nos países africanos estão entre os mais baixos do mundo; em muitos países, há mais do que 60 alunos para um professor; em países como a Etiópia, Nigéria e Zâmbia, mais de metade dos alunos na escola não estão aprendendo habilidades básicas para concluir o ensino primário; metade da população total da escola primária subsaariana - 61 milhões de crianças chegará à adolescência sem as habilidades básicas necessárias para levar uma vida de sucesso e produtiva; os números relativos à educação e pobreza extrema apresentam um percentual de adultos com menos de dois anos de escolaridade, revelando as desvantagens que os estudantes pobres, das áreas rurais, enfrentam no acesso à educação, em comparação com os seus homólogos ricos e urbanos - na Etiópia, 68,3\% vivem em situação de extrema pobreza e falta de acesso à educação, em comparação com apenas 13,8\% dos mais ricos; na Tanzânia, cerca de 58\% das crianças entre 5 e 6 anos não vão para a pré-escola.

- Conclusão 5: As políticas públicas de saúde são bem menos abrangentes do que as que temos no Brasil

Razões encontradas: A esperança média de vida na África é de apenas 46 anos; há uma estimativa de 5.500 mortes por AIDS por dia na África; mais de um milhão de pessoas, a maioria crianças com menos de cinco anos de idade, morrem anualmente de malária; sozinha, a África é responsável por $90 \%$ das mortes por malária em todo o mundo - $80 \%$ dessas vítimas são crianças; calcula-se que uma criança na África morre de malária a cada 30 segundos - cerca de 3.000 por dia.

Ao pesquisar sobre os países do continente africano, os alunos foram muito além do que simplesmente acumular informações. Ao comparar a realidade desses países com a brasileira, eles foram capazes de inferir, deduzir e usar as informações coletadas para ampliar os conhecimentos já adquiridos e fortalecer seus argumentos. Para chegar a essas conclusões, os alunos tiveram que identificar e selecionar as ideias mais importantes; estabelecer a compreensão da conexão lógica entre as ideias trazidas pela pesquisa; identificar, construir e avaliar argumentos, detectar possíveis inconsistências e erros comuns ao raciocinar sobre os fatos; refletir sobre as justificativas a serem dadas, de acordo com suas crenças e valores, dentre outros (Bean, 2011). Na verdade, esse tipo de atividade proporcionou muitos benefícios, tanto para alunos quanto para professores, conforme observações realizadas e relatadas a seguir. 


\section{Avaliação da experiência: os alunos em foco}

Vários benefícios foram percebidos durante as 20 aulas designadas para esse projeto, entre eles: a) melhoria da atenção e capacidade de observação; b) percepção de como clarificar o seu próprio ponto de vista mais facilmente, a partir das informações encontradas; c) desenvolvimento das habilidades de análise, que permitiu escolher ideias e fatos para aplicar nas diferentes situações apresentadas pelos diversos países pesquisados; d) melhoria da compreensão dos alunos sobre seu próprio processo de pensamento. Tudo isso demandou uma operacionalização que, além da articulação de ideias, implicou em questionamentos, consideração dos argumentos e busca de evidências para avaliar a legitimidade de cada ideia, ou seja, uma construção cognitiva multifacetada, com uma natureza indutiva, dedutiva e criativa, compreendendo um conjunto heterogêneo de habilidades, presumindo um repertório de ações, que implicaram em pensamento crítico (Facione, 2010).

Assim, diferentemente de um modelo passivo, em que os alunos decoram fatos fora do contexto, eles tiveram a oportunidade de desenvolver várias habilidades, tais como: a) trabalho em equipe, b) resolução de problemas, c) coleta de dados e informações, d) gestão do tempo, e) síntese de informações, f) resolução de conflitos e g) utilização de ferramentas de alta tecnologia. Ainda, foram reforçadas as habilidades de comunicação interpessoal e trabalhadas as aptidões necessárias para a apresentação das atividades para os colegas. Vale destacar que, para preparar as apresentações, eles elaboraram slides em Power Point, tendo aprendido essa modalidade com o professor de informática.

Trabalhar de maneira integrada também proporcionou compreensão intercultural, além de saber como e quando usar a tecnologia e escolher a ferramenta mais apropriada para cada exercício. Essa combinação de habilidades possibilitou aos alunos mais independência; possibilitando a eles tornarem-se diretores e gerentes de seu processo de aprendizagem, guiados, orientados e mediados pelos docentes e pelos seus pares discentes (Kidd e Czerniawski, 2010). O engajamento nas atividades trouxe qualidade aos trabalhos, que foram melhorando à medida que os alunos levavam cada vez mais a sério as tarefas, afinal, cada uma delas tinha um objetivo específico e crescia em complexidade.

\section{Avaliação da experiência: os professores em foco}

Mais do que simplesmente passar um assunto novo, as atividades de aprendizagem trouxeram benefícios extras ao conteúdo aprendido; elas foram compartilhadas, todo o tempo, por professores e alunos, possibilitando que os docentes também aprendessem com os dados e informações coletadas. Isso proporcionou descartar a noção de que ter um 'kit de ferramentas' pré-elaborado para usar em sala seja mais fácil; na verdade, tais procedimentos tolhem a autonomia e, às vezes, tornamse muito engessantes. Os propósitos pedagógicos, que envolveram os trabalhos 
realizados nesse projeto, constituíram-se em uma fábrica de construção e produção de aulas e recursos, que permitiram que os professores se tornassem mais independentes do livro didático.

$\mathrm{Na}$ contramão de ter um kit de ferramentas pré-elaborado, cada aula era uma surpresa e, embora as diretrizes fossem as mesmas, cada turma e cada grupo trabalharam de forma única, porque as escolhas eram personalizadas. Assim, tudo era compartilhado, inclusive a construção das aulas, que tomavam rumos diferentes, dependendo do resultado das pesquisas realizadas pelos alunos. Essa é uma flexibilidade, às vezes, bastante inquietante e angustiante, já que não há respostas prontas nos livros didáticos e demanda lidar todos os dias com surpresas em termos de conteúdo e planejamento, mas que se justifica pelos resultados encontrados.

Tudo isso contribui para a reflexão do professor sobre o fazer em sala de aula, agregando qualidade ao processo de ensinar/aprender. Questionar o porquê de determinada estratégia de trabalho pode levar ao questionamento de como se pode adaptá-la, o que pode conduzir à criação de novas estratégias próprias, elaboradas de maneira única para o desenvolvimento de um trabalho, também único, proporcionando mais maturidade, aprendizagem e crescimento profissional (Butterworth e Twaittes, 2013). O conhecimento mais ampliado do conteúdo permite desenvolver múltiplas estratégias para ensinar o mesmo tema, além de compreender e identificar os equívocos que alunos possam cometer. Em última análise, os professores estão mais bem preparados para fazer, desfazer e refazer.

Sem dúvida, é um trabalho que demanda atenção e monitoramento concentrado durante todas as atividades, tendo em vista que os alunos, constantemente, pedem opinião e retorno sobre o trabalho em construção. O professor tem que estar circulando o tempo todo pelo espaço da sala de aula e possuir um direcionamento crítico que lhe permita compartilhar e discutir dados objetivos com base nas análises que estão sendo desenvolvidas em cada aula.

Entretanto, é importante destacar que, diferente dos métodos tradicionais, nessa abordagem, às vezes, o professor se torna aprendiz e os alunos têm a oportunidade de ensiná-lo. E, quando o aluno organiza seus pensamentos para explicar suas ideias a seus professores e seus companheiros de equipe, ele se envolve em elaboração cognitiva, o que aumenta e consolida a sua própria compreensão (Slavin, 2011).

\section{Considerações finais}

O presente trabalho mostrou conjugar um trinômio importante para a tarefa de ensinar/aprender: Eficiência, Eficácia e Acessibilidade. Foi eficiente e eficaz ao aumentar a motivação dos alunos, desafiando-os e envolvendo-os em sua própria aprendizagem; promoveu a geração de estratégias próprias para a definição de 
problemas, coleta de informações, análise de dados e o compartilhamento de estratégias com os outros estudantes.

Foi eficiente e eficaz, também, em permitir que os alunos trabalhassem cooperativamente em um ambiente centrado neles, em que foram incentivados a explorar vários temas de interesse. Ele também ofereceu oportunidades de aprendizagem interdisciplinar, envolvendo-os na aplicação do conteúdo das diferentes áreas do conhecimento, ajudando os estudantes a desenvolverem habilidades do mundo real, tais como a capacidade de colaborar com os outros, comunicar-se, tomar decisões, ter iniciativa e enfrentar problemas complexos, por meio da reflexão sobre questões que estão presentes na sociedade contemporânea, tais como, a diversidade étnica.

Em termos de acessibilidade, os alunos construíram a compreensão no contexto da sua própria atividade. Eles progrediram do concreto para um pensamento mais abstrato, do figurativo para aspectos operativos da cognição. Neste sentido, todos os envolvidos neste projeto tiveram acesso a um ambiente que proporcionou aprendizagem e que respeitou o conhecimento prévio individual, o qual se adaptou às novas informações que estavam sendo apresentadas.

$\mathrm{O}$ trabalho em equipe, às vezes barulhento, não foi sinônimo de tumulto $\mathrm{e}$ desorganização. Antes disso, observou-se a iniciativa dos alunos no cumprimento das tarefas, distribuídas entre os componentes de cada grupo, em concordância com todos. Nesse exercício, os alunos mais tímidos foram incluídos e a interação face a face foi promotora de sucesso por meio de elogios, encorajamento, apoio e assistência uns aos outros.

Além da iniciativa, verificou-se a interdependência positiva (Barth, 2011), já que todos precisavam desempenhar suas funções para a tarefa ser concluída, e cada membro do grupo tinha sua função e responsabilidade, mas dependia dos demais para alcançar as metas ou tarefas compartilhadas. Os alunos estavam cientes dos seus papeis e funções específicas dentro do grupo e sabiam que, sem a ajuda de qualquer um deles, a equipe não seria capaz de alcançar o objetivo proposto.

Houve a prática e o desenvolvimento de habilidades sociais como resultado da interação cooperativa, em que o grupo define o cenário para que sejam exercitadas/ aprendidas tais habilidades, que ajudam a construir uma cooperação mais estreita entre a equipe. Liderança, tomada de decisão, construção de confiança e comunicação são diferentes habilidades que foram desenvolvidas nos grupos, que atuaram cooperativamente. Além disso, cada aluno foi responsável por assegurar que os outros membros da equipe desempenhassem o que lhes foi atribuído e, ao mesmo tempo, cada um foi responsabilizado por seu trabalho. Essas habilidades ajudaram a construir uma cooperação mais estreita entre os participantes.

Ainda, aqueles que entenderam melhor os conteúdos foram responsáveis por esclarecer as dúvidas dos outros colegas. Observou-se que os grupos somente progrediam para um novo item, quando todos os membros já tinham dominado o 
conteúdo anterior, condição que favoreceu a inclusão estimulada pelo trabalho colaborativo.

Concluindo, os alunos estiveram expostos à investigação de problemas autênticos e foram apoiados durante todos os trabalhos, pelos professores, colegas de grupo e turma. $\mathrm{O}$ trabalho cooperativo e colaborativo proporcionou a formação de alianças, alavancando os pontos fortes de cada um, com a ajuda dos parceiros. Então, pode-se afirmar que houve incentivo à aprendizagem como construção do conhecimento, aliado a um contexto social crítico, em uma comunidade de aprendizagem, em que os conceitos aprendidos dos conteúdos abordados estiveram balizados no distanciamento de uma concepção mecânica e repetitiva, comuns ainda em muitos fazeres pedagógicos.

\section{Referências}

Alvarez, S. E. Dagnino, E., Escobar, A. (2000). (Org.). Cultura e política nos movimentos sociais latino-americanos: novas leituras. Belo Horizonte (MG): UFMG.

Atherton, J. S. (2013). Learning and Teaching; Piaget's developmental theory. Recuperado em 21 de abril de 2015, de http://www.learningandteaching.info/ learning/ piaget.htm.

Ausubel, D. P. (1962). A subsumption theory of meaningful verbal learning and retention. The Journal of General Psychology, 66, 213-244.

Barth, F. (2011). Grupos étnicos e suas fronteiras. In P. Poutignat, J. Streiff-Fenart. Teorias da etnicidade: seguido de grupos étnicos e suas fronteiras de Fredrik Barth, pp. 185-227. São Paulo: Unesp.

Bean, J. C. (2011). Engaging Ideas: The Professor's Guide to Integrating Writing, Critical Thinking, and Active Learning in the Classroom. Toronto: Wiley.

Bohonos, J. (2013). Key theories of Lev Vygosky and John Dewey: Implications for academic advising theory. Academic Advising Today, 36(2), 23-35.

Brasil. (2006). Ações para a educação das relações étnico-raciais. Brasília: SECAD/MEC.

Bruner, J. e Haste, H. (1987). Making sense: the Child's Construction of the world. Londres: Methuen.

Butterworth, J. e Twaittes, G. (2013). Thinking skills: critical thinking and problem solving. Cambridge: Cambridge University Press.

Campbell, J. (1995). Understanding John Dewey. Nature and co-operative intelligence, Chicago: Open Court.

Dewey, J. (2011). Democracy and Education. Milton Keynes: Simon and Brown. 
Egan, K. e Judson, G. (2008). Of whales and wonder: By using cognitive tools to shape instruction, we can make the curriculum more imaginatively engaging. Educational Leadership, 65(6), 20-25.

Facione, P. A. (2010). Critical thinking: What it is and why it counts. Califórnia: Insight Assessment. Recuperado em 15 de abril de 2015, de http://www.insightassessment.com/home.html.

Feldman, R. S. (2010). Child Development. Nova Jérsei: Pearson Prentice Hall.

Freire, P. (2006). Ação cultural para liberdade e outros escritos. São Paulo: Paz e Terra.

Kidd, W. e Czerniawski, G. (2010). Successful Teaching 14-19: Theory Practice and Reflection. Londres: Sage Publications.

Santos, J. L. (2011). Raça/etnia, cultura, identidade e o professor na aplicação da Lei 10639/2003 e as aulas de língua inglesa: como?. Dissertação de Mestrado em Estudos de Linguagens - Universidade do Estado da Bahia (UNEB) - Salvador.

Slavin, R. E. (2010). Co-operative learning: What makes groupwork work? In H. Dumont, D. Istance e F. Benavides (Eds.). The nature of learning: Using research to inspire practice. pp. 161-178. Paris: OECD.CL.

Slavin, R. E. (2011). Instruction based on cooperative learning. In: R. Mayer (Ed.), Handbook of research on learning and instruction. Instruction Based on Cooperative. pp. 334-360. Londres: Taylor \& Francis.

Valadares, J. A e Moreira, M. A. (2009). A teoria da aprendizagem significativa: sua fundamentação e implementação. Coimbra: Edições Almedina S.A.

Vygotsky, L. S. (1978). Mind in society: The development of higher psychological process. London: Harvard University Press.

Data de recebimento: 14/05/2016

Data de revisão: 11/06/2016

Data do aceite: 20/07/2016 